\title{
Seismic performance assessment of a timber log house
}

\author{
J.M. Branco, P.B. Lourenço \& C. Aranha \\ ISISE, Civil Engineering Department, University of Minho, Guimarães, Portugal
}

\begin{abstract}
The current work presents a full scale shaking table test conducted on a twostoreyed timber log house, designed according to the state of the art on timber engineering. The test was performed within the framework of the SERIES Project "Multi-storey timber buildings" at LNEC, Lisbon, Portugal. Several tests and studies have been carried out by the University of Minho to characterize the behavior of the different components (logs, walls, slabs, connections, etc.) of log houses in the past few years for the European Technical Approval (ETA) of this construction system. The main results of the shaking table test are presented along with the preliminary analysis of the overall behavior of the log house. The analysis was carried out based on the shaking table tests and on a numerical model developed to estimate the main seismic parameters using the data obtained from the different individual studies on each component of the construction system performed within the framework of the ETA.
\end{abstract}

\section{INTRODUCTION}

The construction of timber houses using logs is an ancient practice in many regions of the globe. In those times, the gaps between the logs were filled with moss. With the emergence of other construction materials, the use of timber decreased considerably and the log system lost importance. Nevertheless, timber log constructions are still popular in many forest regions of the world, especially in North America and Scandinavia. Although this form of construction has been in use since a very long time, the amount of data available on the structural behavior, the seismic capacity and other properties is limited.

Log buildings rely on the walls built stacking horizontal layers of logs, for resistance to both vertical and horizontal loads. The resistance to vertical loads depends mostly of the contact area between logs and the strength in compression perpendicular to the grain, while horizontal loads are supported by transverse walls, depending strongly on the friction between the joints.

The resistance to lateral loads in log shear walls depends on the (1) interlocks between logs, (2) wood or steel dowels, (3) vertical through bolts and anchor-bolts, and, (4) frictions between logs due to vertical loads. However, current codes only consider the influence of dowels and vertical through bolts (Hirai et al. 2004), as a result of the significant variability and inexistence of accurate models for the other resistance mechanisms. Friction is not regarded as a resistance mechanism.

During the European Technical Approval (ETA) of a Portuguese log house construction system developed by Rusticasa ${ }^{\circledR}$, performed by the University of Minho (UMinho), several experimental and numerical studies have been performed to make a detailed characterization of the construction system. In terms of mechanical properties, the logs were characterized (under bending and compression loads) and the most representative connections were tested under monotonic and cyclic loading. Connections between logs, between walls and the connection of the walls with the foundation were studied by means of numerical and experimental studies. 
Moreover, in-plane static tests were conducted on timber log walls with distinct transversal stiffness, two vertical compression levels and different values of slenderness to assess the structural behavior of log timber walls under lateral in-plane loads. Those studies (Branco and Araujo, 2012), represent a further step in the knowledge of log-houses about which little previous information existed.

Within the framework of the SERIES Project 'Multi-storey timber buildings', coordinated by the University of Trento and involving the University of Minho and TU Graz, full scale shaking table tests on a full scale log house have been performed. Shaking table tests were essential to assess the seismic performance of this type of timber construction, while the previous studies on its individual resistance mechanisms allowed to predict, with good accuracy, the overall behavior of the specimen through a numerical model (FEM).

In this paper, the geometry of the two storey timber log house tested and its structural details are presented. The main results of the shaking table test are presented and a first analysis of the overall behavior of the log house are described based on the shaking table tests and on the different individual studies on each component of the construction system, performed within the framework of the ETA.

\section{THE TEST BUILDING}

\subsection{Geometry}

The building is characterized by a rectangular plan of size $5.64 \mathrm{~m} \times 7.3 \mathrm{~m}$. The logs used in the construction of the walls are machined and shaped both at the top and bottom to improve stability and increase the area of contact. The dimensions of the cross sections of the logs are $160 \mathrm{~mm}$ $\mathrm{x} 160 \mathrm{~mm}$ and $80 \mathrm{~mm} \times 160 \mathrm{~mm}$ for the outer and inner walls, respectively. The logs are made of glulam with 4 and 2 lamellas of $40 \mathrm{~mm}$ thickness, respectively. The lamellas are composed of Scots pine (Pinus sylvestris L.) of the strength class C24 according to CEN (2003). Additional information about the geometry and the mechanical characterization of the logs can be found in (Branco and Cruz, 2008).

The structure is symmetrical in the longitudinal direction and asymmetrical in the transverse direction. The floor beams are of size $90 \mathrm{~mm} \times 165 \mathrm{~mm}$ and are connected to the walls by dovetail joints. In order to guarantee rigid in-plane behavior of the floor diaphragm, the beams are superimposed by Oriented Strand Board (OSB) panels of $22 \mathrm{~mm}$ thickness. The height of the walls on the top-most floor increases from $4.40 \mathrm{~m}$ at the edge to $5.28 \mathrm{~m}$ at the ridge, forming a traditional gable roof. The roof structure is characterized by massive wooden rafters inclined at an angle of $18^{\circ}$, over which $12 \mathrm{~mm}$ thick OSB panels are nailed. The section of the rafters is $70 \mathrm{~mm}$ $\mathrm{x} 190 \mathrm{~mm}$ while the ridge has a cross-section of $120 \mathrm{~mm} \times 200 \mathrm{~mm}$.
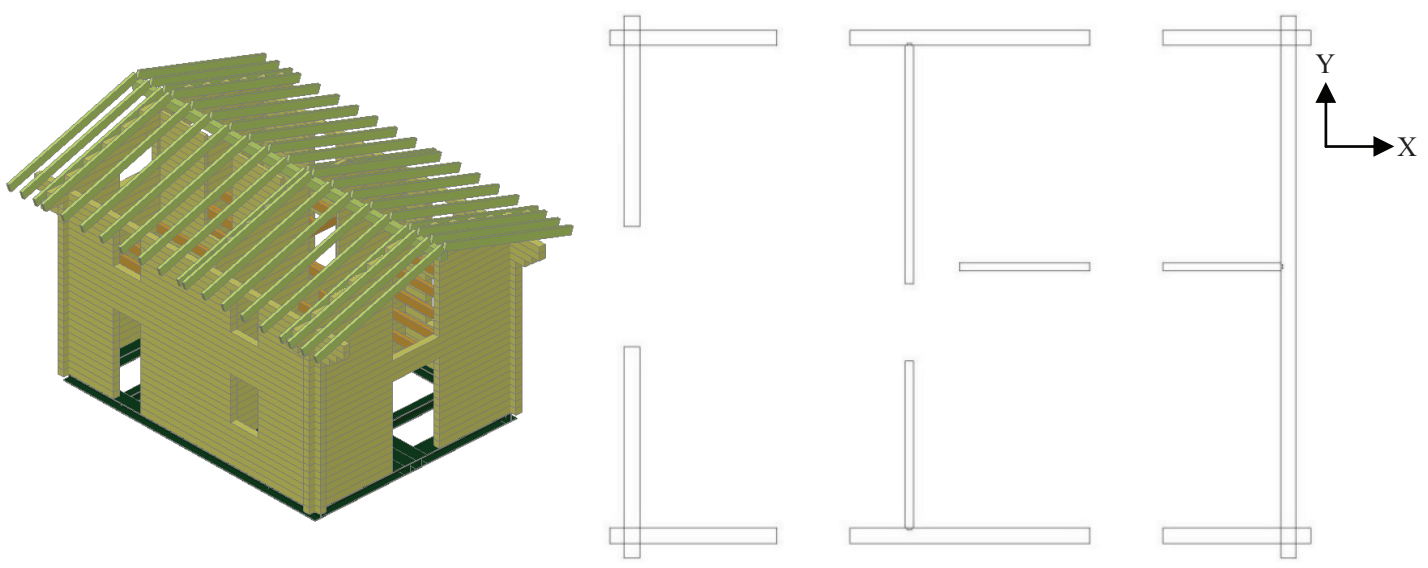

Figure 1. 3D model (left) and plan view (right) of the two-storeyed log house tested 


\subsection{Structural connections}

The interceptions between orthogonal walls are in the form of halved joints when two exterior walls meet and dovetail joints when an exterior wall meets an interior wall. The floor end joists are also appropriately grooved so as to fit in perfectly with the log walls. The first logs are connected to the foundation (steel base) through M16 bolts of Class 8.8 that are spaced at intervals of $500 \mathrm{~mm}$. This ensures that no sliding occurs between the log house and the steel base. The connections between orthogonal walls, floor beams to the walls as well as the connection between first logs and the steel base can be seen in Figure 2.

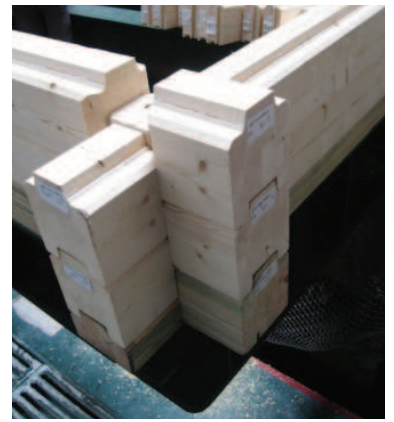

(a)

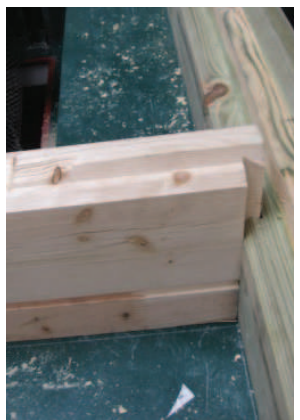

(b)

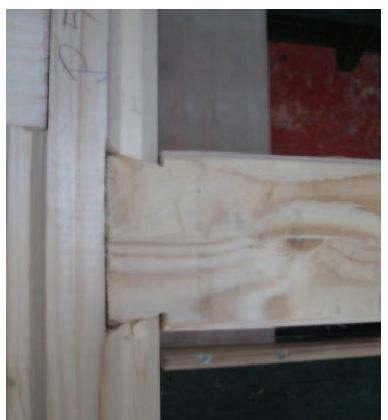

(c)

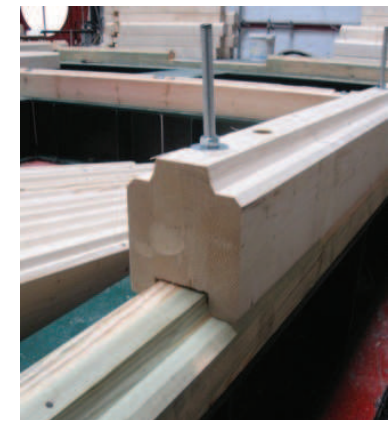

(d)

Figure 2. Connections between (a) two exterior walls (b) an exterior and an interior wall (c) floor beam and wall (d) first log and foundation

To ensure the in-plane stiffness of the walls, $10 \mathrm{~mm}$ screws $(10 \mathrm{~mm} \times 140 \mathrm{~mm})$ were used around the openings and $8 \mathrm{~mm}$ screws $(8 \mathrm{~mm} \times 240 \mathrm{~mm})$ in the connections between orthogonal walls. To connect the rafters of the roof structure, $10 \mathrm{~mm}$ screws $(10 \times 140 \mathrm{~mm})$ and $40 \mathrm{~mm} \times 140 \mathrm{~mm}$ steel plates were used near the ridge while $6 \mathrm{~mm}$ screws $(6 \mathrm{~mm} \times 120 \mathrm{~mm})$ were used to make the connection between the rafters and the top of the walls. Figure 3 presents the details of the structural connections made with screws.
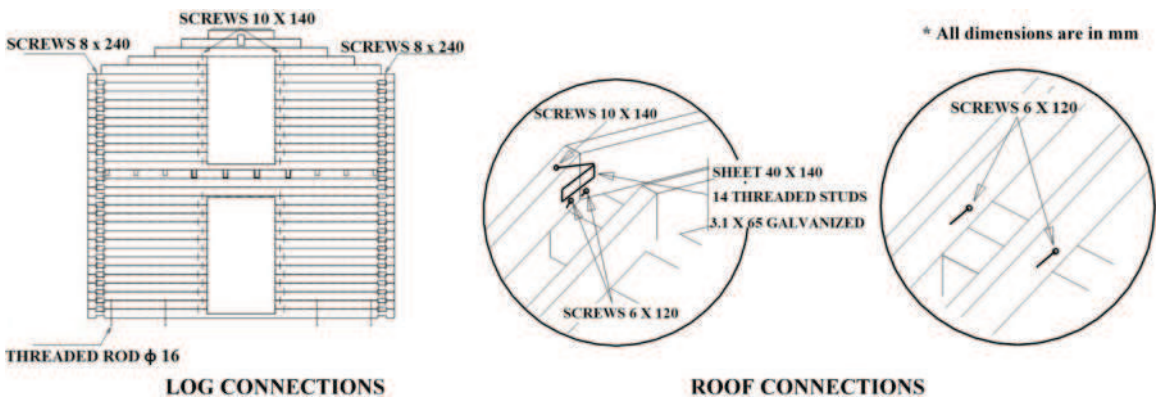

Figure 3. Structural screwed connections used in the log-house tested

\section{SHAKING TABLE TESTS}

\subsection{Assembly}

The shaking table is a triaxial platform that has three independent translational degrees of freedom, with rotational ones minimized with the aid of a torque tube system. As the shaking table at LNEC wasn't large enough to directly accommodate the building, a steel lattice was used to connect the structure to the table and provide a wider base.

The steel base is composed of two identical rectangular sections which are $7 \mathrm{~m}$ long and $2.675 \mathrm{~m}$ wide that are rigidly connected together. Figure 4 shows the plan and the structure of the steel base. 

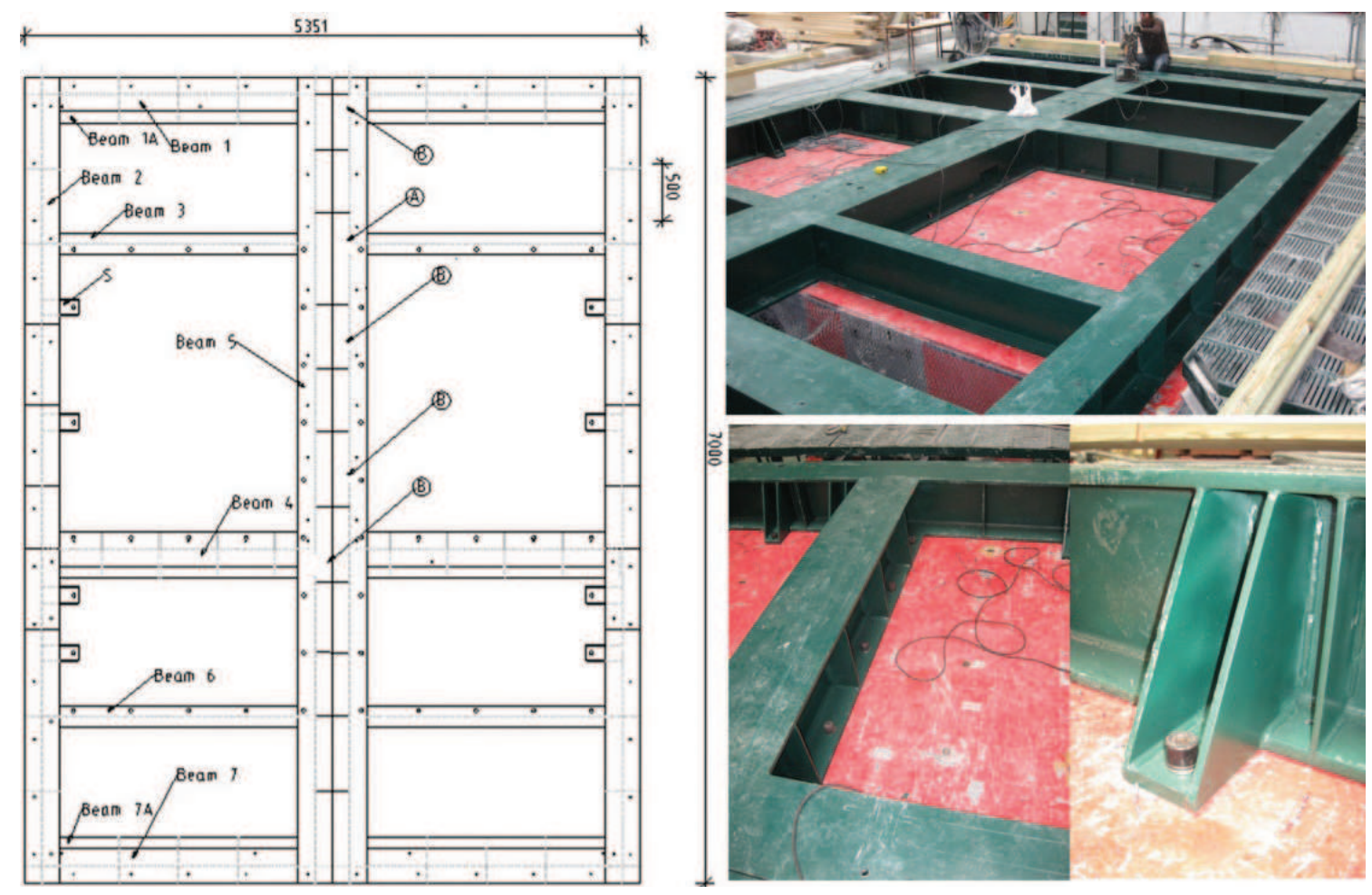

Figure 4. The steel base - plan (left), structure (top right) and connections (bottom right)

All structural elements of the building were prefabricated in the factory Vila Nova de Cerveira and then transported by truck to Lisbon, over a distance of about $400 \mathrm{~km}$. The assembly of the building was done directly over the shaking table and took four days by 3 workers. The various stages of assembly are showed in Figure 5.

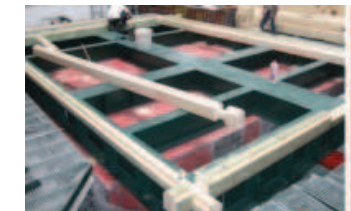

(a)

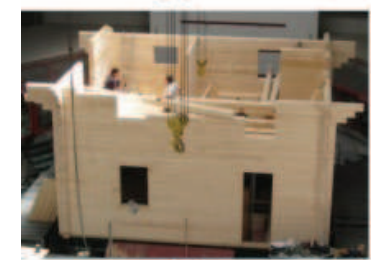

(e)

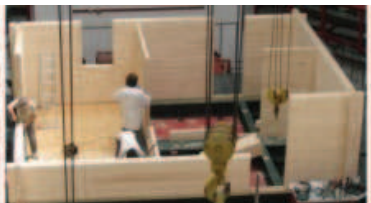

(b)

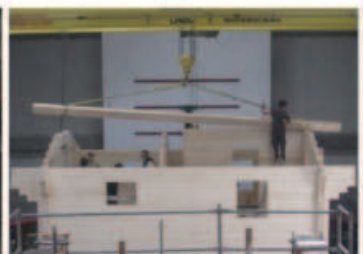

(f)

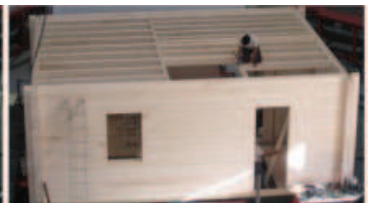

(c)

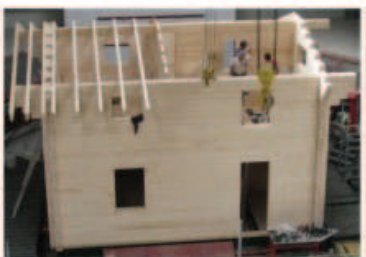

(g)

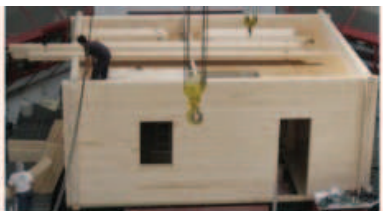

(d)

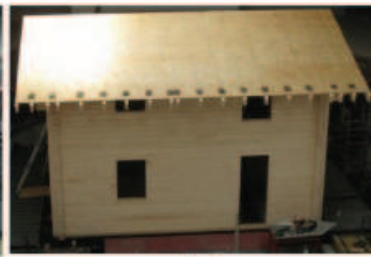

(h)

Figure 5. Stages of construction (a) Connecting the sill logs with the foundation (b) building the ground floor walls (c) installing interstorey floor beams (d) nailing OSB planks to the floor joists (e) building the first floor walls (f) positioning the ridge board (g) laying the roof rafters (h) completed house

\subsection{Instrumentation}

A total of 80 instruments placed at different points of interest in the building along with an optical acquisition system were used to monitor the building. The optical acquisition system consisted of infrared cameras and linear position sensors which are able to continuously detect and measure absolute displacement of the control points. The instruments were arranged to mainly study the behavior of the building in the longitudinal and transverse directions. The monitoring 
system focused on studying the behavior of five walls on each floor (Figure 6), two in the longitudinal direction and three in the transverse direction.
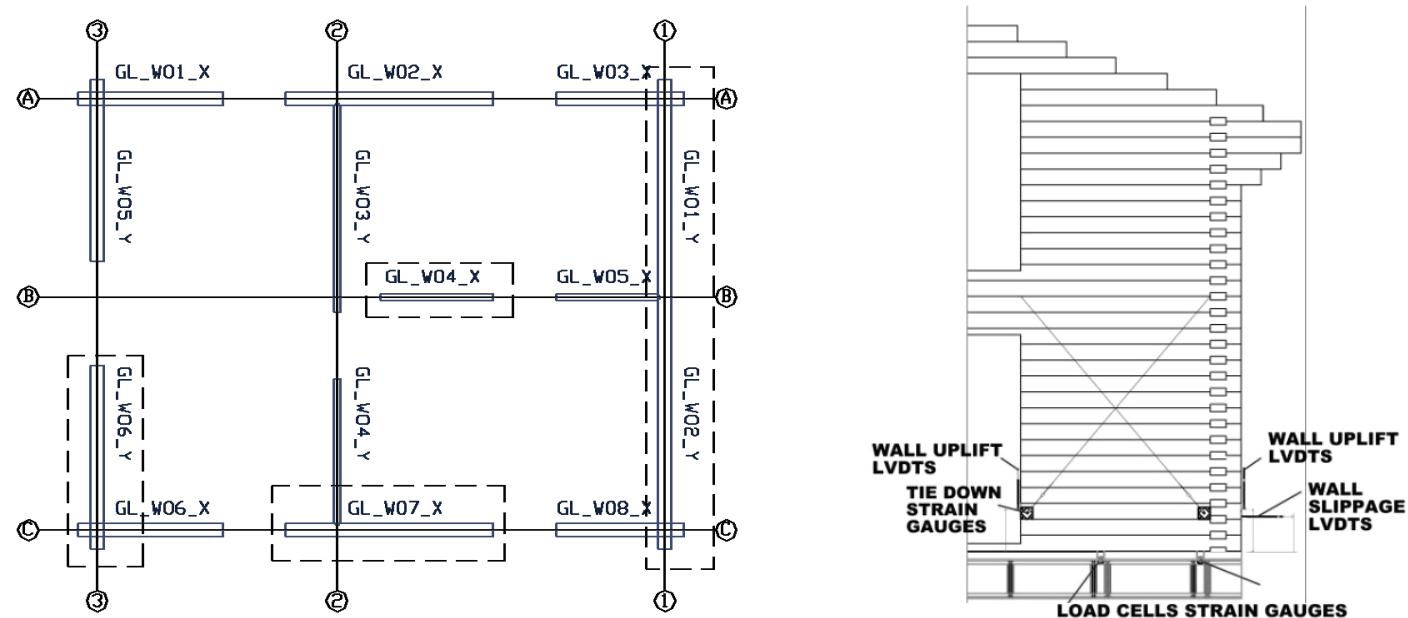

Figure 6. Monitored walls (Ground floor) and detail of the instrument locations in wall W06_Y

The force acting on different structural components was measured by load cells placed strategically and the accelerometers placed at each floor measured the acceleration values and also monitored the out-of-plane behavior of the walls.

Twenty-two LVDTs were used to monitor the deformations of shear walls, the vertical lift, horizontal movement and inter-storey drifts. The indicator scrolls in the form of a vertical line along the height of the wall served as an indicator for slippage between the logs. The data obtained during all the stages of testing was sampled at a sampling frequency of $125 \mathrm{~Hz}$.

Figure 7 shows the location of the accelerometers, load cells and inter-storey displacement LVDTs while Figure 8 shows the instruments used.

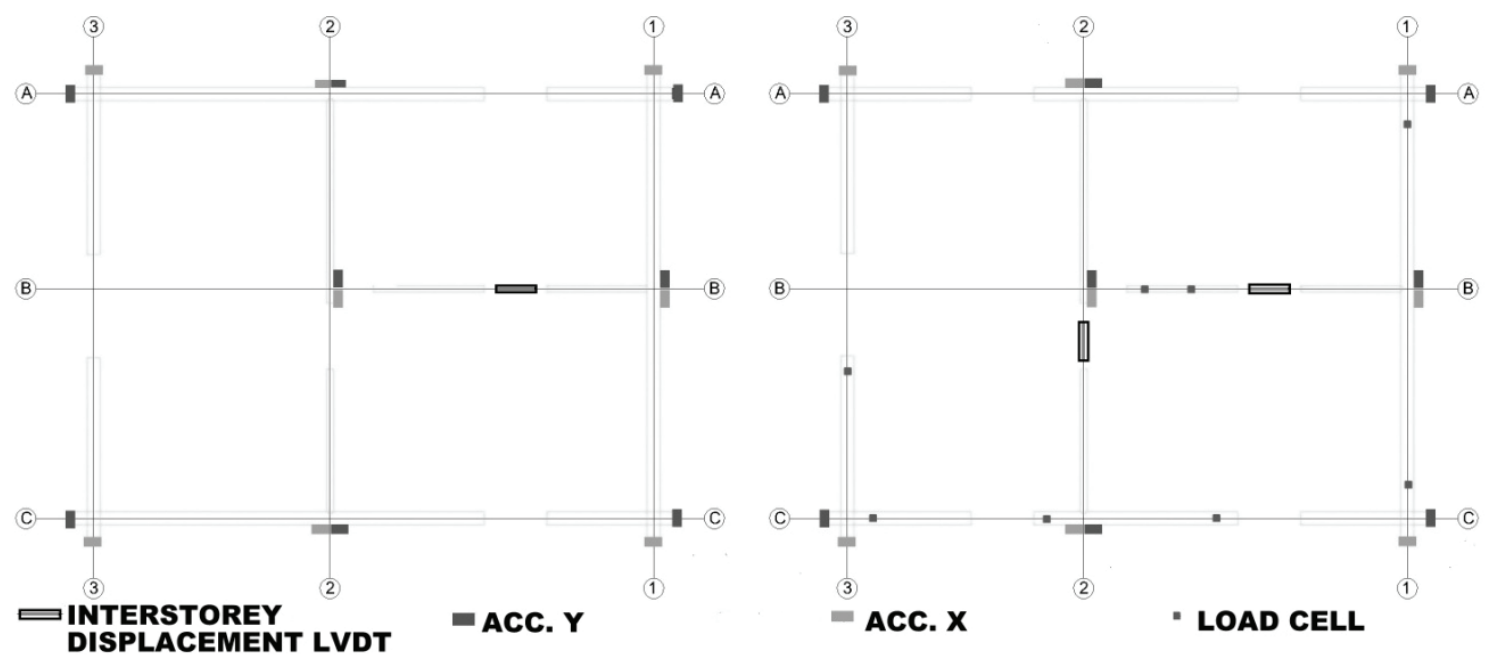

Figure 7. Location of the accelerometers, load cells and inter-storey displacement LVDTs on the first floor (left) and ground floor (right) 


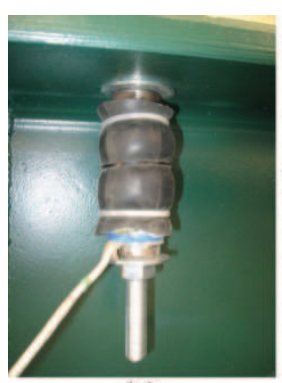

(a)

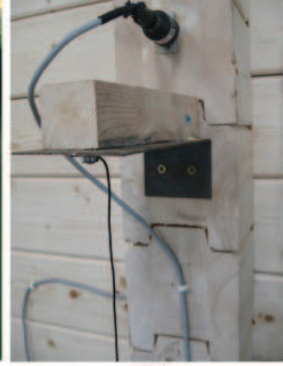

(b)

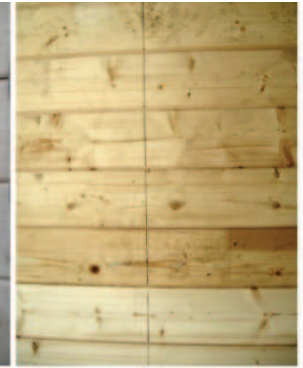

(c)

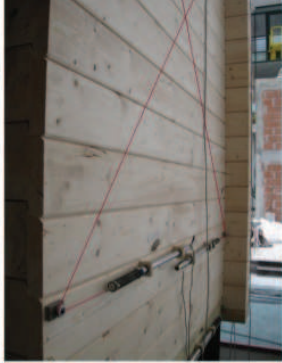

(d)

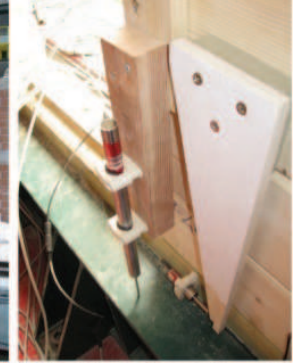

(e)

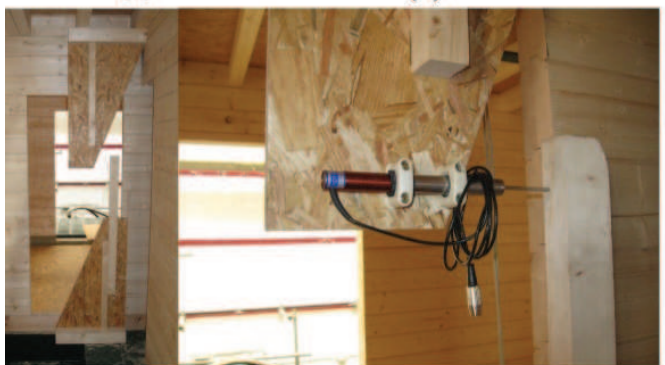

(f)

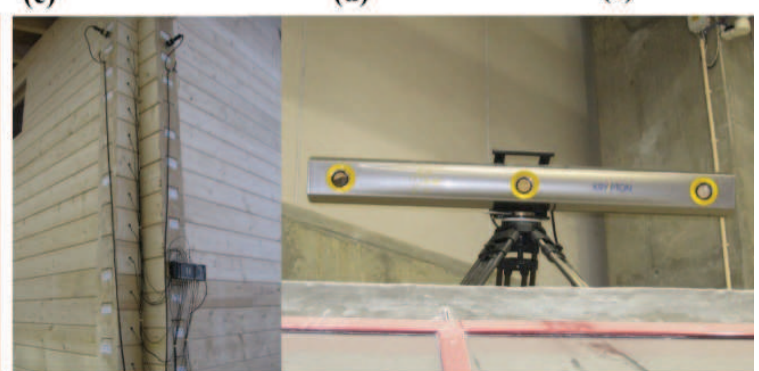

(g)

Figure 8. (a) load cell (b) accelerometer (c) indicator scroll (d) shear deformation LVDT (e) LVDT to measure sliding of walls (f) interstorey displacement LVDT (g) Optical acquisition system

\subsection{Testing procedure}

Based on the pre-design of the test, the input signal chosen was the one that was registered at the Ulcinj - Hotel Albatros during the Montenegro earthquake on the 15th of April 1979 $(\mathrm{Mw} 6,9)$. The properties of the earthquake are reported in the European Strong Motion Database (http://www.isesd.hi.is/ESD Local/frameset.htm). The acceleration time history in the $\mathrm{x}$ and y directions were used and the peak ground accelerations were $0.181 \mathrm{~g}$ and $0.224 \mathrm{~g}$, respectively (Figure 9).
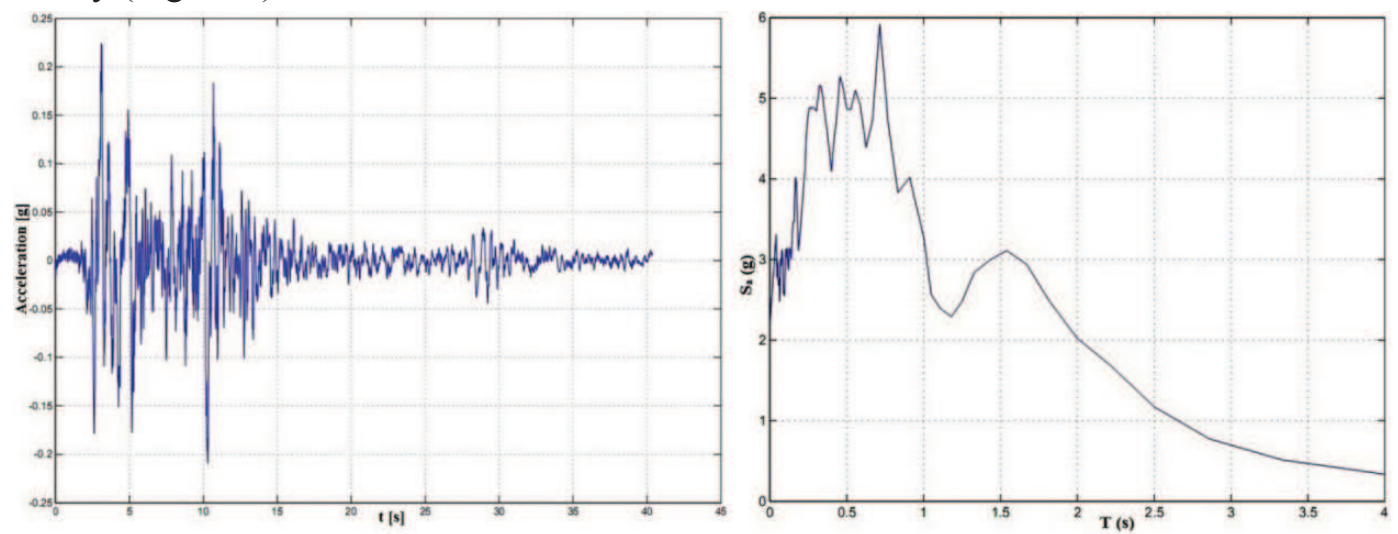

Figure 9. The accelerogram (left) and response spectrum (right) of the Montenegro earthquake recorded at the Ulcinj- Hotel Albatros station

All seismic tests were preceded and followed by a dynamic test at low intensity, in the form of white noise. The acceleration time history was characterized by a Gaussian distribution of RMS of $0.05 \mathrm{~g}$ and a frequency band approximately constant between $0.1 \mathrm{~Hz}$ and $30 \mathrm{~Hz}$. The purpose of these tests was to calibrate the parameters necessary to control the vibrating table and to conduct the dynamic identification of the structure.

The test procedure followed was carried out in three stages beginning for PGA values of $0.07 \mathrm{~g}, 0.28 \mathrm{~g}$ and $0.5 \mathrm{~g}$. 


\section{RESULTS}

\subsection{Fundamental period}

After the instrumentation set-up was complete, the verification of their working condition was carried out along with the calibration of the optical acquisition system. A first frequency evaluation test was performed to identify the fundamental period (or frequency), mode shapes and damping of the structure. In this stage, a fundamental period of $\mathrm{T}=0.197 \mathrm{~s}$ (frequency, $\mathrm{f}=5.07 \mathrm{~Hz}$ ) was obtained. This value is similar to the one obtained by the numeric model previously developed to estimate the main parameters of the shaking testing program (Figure 10). The preliminary numerical model made to predict the main seismic parameters, was built using the geometry defined by Rusticasa ${ }^{\circledR}$ and assuming the material properties obtained in the several numerical and experimental studies performed by UMinho (Branco and Araujo, 2012), indicated a fundamental period of $0.201 \mathrm{~s}(\mathrm{f}=4.97 \mathrm{~Hz})$. This result shows the accuracy of the numeric model defined in a preliminary step of the research aiming to prepare the shaking table tests.
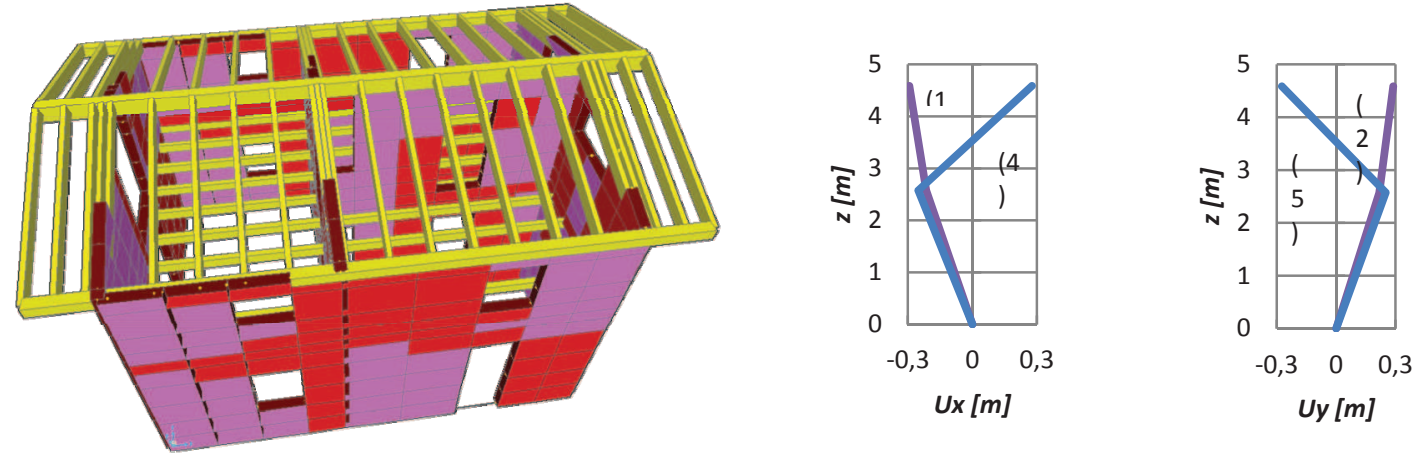

Figure 10. 3D FEM model in SAP2000 and representative translational mode shapes (number inside brackets) in the $\mathrm{x}$ and $\mathrm{y}$ directions.

The first mode shape corresponds to a translational movement in the x-direction (longitudinal axis), the second mode shape, close to the first one ( $\mathrm{T}=0.197 \mathrm{~s})$ corresponds to a translational movement in the y-direction while the third mode is a torsional one and is represented by a rotation around the z-axis. With regard to the damping of the structure, the value indicated by the numeric model is much higher than the value typically assumed by codes and recommendations for timber structures $(\xi=5 \%)$.

\subsection{Visible damages}

During the incremental test procedure, whenever damage occurred, an identification test was performed to assess any variation in the fundamental period of the house. While the first two stages of the test with maximum accelerations of $0.07 \mathrm{~g}$ and $0.28 \mathrm{~g}$ produced no visible damage in the building, some minor damages were seen after the building was subjected to a PGA of $0.5 \mathrm{~g}$. No kind of repair intervention was carried out between the successive stages of the experiment.

Some of the damages observed after the tests (see Figure 11) were:

- Fracture along the length of the log due to out-of-plane flexure;

- Fracture along the grain at connections between orthogonal walls due to shear;

- Slipping of logs due to shear;

- Damage in the vicinity of the screws;

- Internal cracks in the log section;

- Fracture at the top and bottom notches of the logs. 

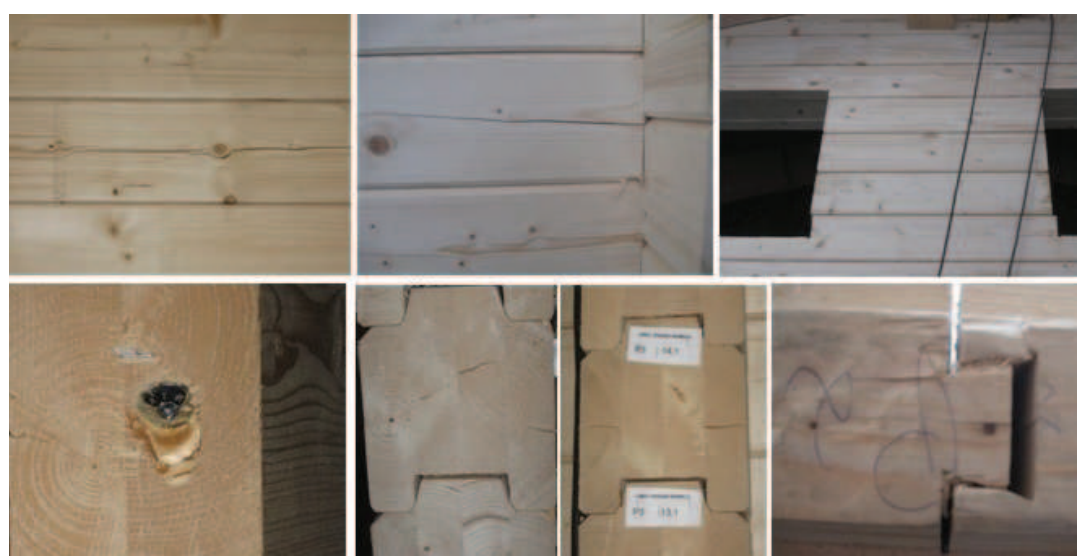

Figure 11. Damages observed in the building after the 0.5g PGA test

\section{CONCLUSIONS}

The present work intends to improve the existing knowledge on timber log-houses subject to seismic events through an experimental approach. The analysis of the seismic behavior of a two-storeyed model log construction formed the final phase of an experimental research project on this specific type of construction, undertaken by the University of Minho in partnership with the Portuguese company Rusticasa ${ }^{\circledR}$. The test was performed within the framework of the SERIES Project 'Multi-storey timber buildings', coordinated by the University of Trento and involving the University of Minho and the TU Graz, at LNEC, Lisbon, Portugal. The main results of the shaking table test have been presented and a first analysis of the overall behavior of the timber log-house was described. A fundamental period of $\mathrm{T}=0.197 \mathrm{~s}$ (frequency, $\mathrm{f}=5.07 \mathrm{~Hz}$ ) was obtained while the numerical model used to estimate the main parameters of the shaking testing program, assuming the material properties obtained in the several numeric and experimental studies performed by UMinho (Branco and Araujo, 2012) in previous steps of the research, indicated a fundamental period of $0.201 \mathrm{~s}(\mathrm{f}=4.97 \mathrm{~Hz})$. No visible damage was observed in the construction for the stage tests with maximum accelerations of $0.07 \mathrm{~g}$ and $0.28 \mathrm{~g}$, while some minor damages were observed after the building was subjected to a PGA of $0.5 \mathrm{~g}$.

\section{FUTURE DEVELOPMENTS}

The next step of the research is the detailed analysis of the results recorded by all instruments during the shaking table testing program performed.

\section{ACKNOWLEDGEMENT}

The authors gratefully acknowledge the SERIES project "Seismic performance of multi-storey timber buildings" for financing the study, to University of Trento, LNEC and TU Graz the discussion took to prepare the tests and Rusticasa ${ }^{\circledR}$ to provide the specimen to be tested.

\section{REFERENCES}

Branco, J.M., Araújo, J.P. 2012. Structural behaviour of log timber walls under lateral in-plane loads. Engineering Structures. 40 (2012), 371-382. URI: http://hdl.handle.net/1822/19907

Branco, J.M., Cruz, P.J.S. 2008. Caracterização Mecânica de Toros de Madeira Lamelada Colada. $7^{o}$ Congresso Nacional de Mecânica Experimental, UTAD, 23-25 January (in Portuguese).

CEN, 2003. Structural timber - Strength classes. EN 338:2003, European committee for standardization, Brussels, Belgium.

Hirai, T., Kimura, T. Yanaga, K. Sasaki and Y. Koizumi, A. 2004. Lateral resistances of log constructions. Proceedings of the World Conference on Timber Engineering, Volume I.

SAP 2000, CSI Analysis Reference Manual for SAP2000. Version v14. Computers \& Structures Inc., Berkeley, USA. 